\title{
Impact of driving forces on molten pool in gas metal arc welding
}

\author{
Won-lk Cho ${ }^{1}$ (D) $\cdot$ Suck-Joo $\mathrm{Na}^{2,3}$
}

Received: 22 July 2020 / Accepted: 25 April 2021 / Published online: 13 May 2021

(C) The Author(s) 2021

\begin{abstract}
A numerical scrutiny was performed to analyze the effect of driving forces on molten pool in gas metal arc welding. In addition to the basic governing equations required for a general heat and mass transfer analysis by computational fluid dynamics, a volumeof-fluid equation for free surface tracking and additional conservation equations for calculating the distribution of alloy elements were used. Driving forces - buoyancy, drag force, arc pressure, electromagnetic force, Marangoni pressure, and droplet impingement - and the arc heat source were mathematically modeled and applied to the simulation. In order to examine the effect of driving forces, a two-dimensional axisymmetric simulation was performed, and the effect of each driving force was analyzed using the velocity components. In the radial velocity component, the effect of droplet impingement and the Marangoni force was large, and in the vertical velocity component, the droplet impingement effect was dominant. A three-dimensional simulation was also performed considering all the driving forces together, and the result was verified by comparison with experimental results. Relatively high alloying element contents were found at the bottom of the fusion zone, which was due to the droplet impingement generating a high vertical velocity.
\end{abstract}

Keywords Gas metal arc welding $\cdot$ Numerical simulation · Driving forces $\cdot$ Molten pool $\cdot$ Alloying element distribution

\section{Introduction}

Arc welding is a process of melting and joining workpiece using arc plasma heat generated by electric discharge. The arc is composed of ionized gas, which is electrically neutral at high current resulting in high temperatures and strong process light during the process. Consequently, analytical and numerical studies have been actively underway in terms of the welding design, in which modeling of the arc heat source is performed to calculate the residual stress and thermal deformation, and the results are utilized to design the welding structure [1]. In the 1940s, Rosenthal first calculated the shape of

Recommended for publication by Study Group 212 - The Physics of Welding

Won-Ik Cho

wonikcho@gmail.com

1 BIAS - Bremer Institut für angewandte Strahltechnik $\mathrm{GmbH}$, Klagenfurter Straße 5, 28359 Bremen, Germany

2 Department of Mechanical Engineering, KAIST, 291 Daehak-ro, Yuseong-gu, Daejeon 305-701, Korea

3 School of Materials Science and Engineering, Xi'an Jiaotong University, Xi'an 710049, China molten pool in arc welding by using a moving point heat source [2]. The point heat source was applied on the undeformed surface of the workpiece, and only thermal conduction was considered. This approach can be used to predict the temperatures far enough from the arc because the error increases near the arc. To date, the arc assumes as a Gaussian heat source, and welding-specialized software based on the finite element method (FEM) has been commercialized with improved accuracy. Even the residual stress and the deformation considering the phase transformation can be easily calculated [3]. However, the FEM analysis based on the thermal conduction model has a limitation that it cannot directly consider the effect of the molten pool flow.

Therefore, numerical studies to analyze the molten pool flow have been conducted by computational fluid dynamics (CFD). In the early stages, the simulations were performed without considering the molten pool deformation. For this reason, gas tungsten arc (GTA) welding at low current is mainly considered thanks to its small deformation. Kim et al. (1989) analyzed the axisymmetric molten pool in static GTA welding. The driving forces - electromagnetic force, buoyancy, surface tension, and drag by gas - were considered, and the molten pool surface was assumed flat [4]. A numerical study considering the deformed molten pool surface was also conducted [5]. In gas metal arc (GMA) welding, 
a three-dimensional quasi-steady-state heat transfer and molten pool flow analysis considering the deformation of the molten pool surface was performed using a boundary-fitted coordinate system, in which electromagnetic force, buoyancy, and surface tension were considered. The results showed that a long molten pool was created behind the arc, and buoyancy and surface tension had a minor effect on the molten pool shape. A finger-shaped penetration was observed only when the molten pool convection was considered in simulation [6]. In a follow-up research, molten droplets were imposed on the molten pool surface as a velocity distribution with the Gaussian function, and the effect of the contact tip to workpiece distance (CTWD) was examined. It was found that their effects on the molten pool were significant [7]. Lee et al. (1995) performed a numerical study of the arc behavior in GTA welding using the boundary-fitted coordinate system. The actual electrode shape was considered assuming that the current density had the Gaussian distribution. It was possible to predict not only the temperature distribution of the arc but also the current density, heat flow, arc pressure, and drag transmitted [8]. In a further study, effects of the electrode angle and arc length were examined. The results showed that the electrode angle did not significantly affect the heat flow and current density distribution, but it had a great effect on arc pressure and drag compared to the arc length. In particular, the change of the arc pressure was negligible even when the arc length was changed [9]. In the follow-up study, the change of molten pool surface was considered in the arc analysis [10]. An integrated modeling of arc and molten pool behavior was performed as well [11]. In the abovementioned studies, the shape of the molten pool surface was obtained through iterative calculation minimizing the surface total energy. However, the method is not suitable for analyzing cases with a large molten pool deformation like a molten droplet transfer. As an indirect method to consider the droplet transfer, the method of adding the momentum and enthalpy of the droplet [12], the coordinate transformation method [13], and the method of adding the volumetric heat source of the droplet [14] were used. Free surface tracking algorithms (e.g., the volume-offluid (VOF) method) allow direct consideration of molten pools with large surface deformations. Choi et al. (1998) predicted the free surface, velocity, and pressure change in the short-run mode GMA welding using the VOF method [15]. Ko et al. (2000) analyzed the effects of molten pool surface change on flow and vibration in stationary GTA welding using the VOF method [16]. In recent years, a threedimensional transient molten pool analysis of arc welding has been performed in that the computation time is greatly reduced even in a bigger computational domain thanks to the advancement of computing technology and algorithms. A three-dimensional transient molten pool analysis considering the droplet transfer was performed for the fillet joint [17], and an integrated analysis of the arc and the molten pool was also conducted [18]. Pulsed GMA weaving welding analysis was performed for $\mathrm{V}$-groove-shaped welds using the results of dynamic arc behavior analysis based on simplified RL circuit of the welding power supply. The arc heat source distribution obtained by the Abel inversion of the arc shapes observed by a CCD camera was used in simulation [19]. Molten pool behavior in the gas hollow tungsten arc (GHTA) spot welding process was also calculated at a low-pressure-gravity state like in space [20]. Kiran et al. (2015) conducted a three-dimensional simulation to understand the temperature distribution and molten pool behavior in a three-submerged-arc welding process. They showed that weld width was significantly influenced by the leading arc and the penetration by the middle and trailing arcs [21].

In this study, mathematical models presented in the literature were used for GMA welding simulation. In order to examine the effect of the driving force on the molten pool, a 2D axisymmetric simulation was conducted in stationary arc welding, and the maximum velocity components were compared in terms of the driving forces. In the 3D transient analysis, additional conservation equations for the alloying elements were used to calculate the distribution of the alloying elements supplied by the consumable electrode. The models used were verified by comparing the fusion zone shape and the alloy element distribution measured in the experiment.

\section{Methodology}

To analyze the effects of the driving forces (buoyancy, drag, arc pressure, electromagnetic force, Marangoni force, and droplet impingement), the molten pool behavior was calculated in stationary arc welding. Figure 1 shows the 2D axisymmetric computational domain and cylindrical mesh used in the simulation. Table 1 shows the boundary conditions for the computational domain. Table 2 shows the simulation cases for the six driving forces, and for the Marangoni force, and three cases with sulfur contents of $0 \mathrm{ppm}, 130 \mathrm{ppm}$, and $500 \mathrm{ppm}$ were considered. ASTM A36 steel was used in this study, and the reason for selecting the different sulfur contents is as follows: $500 \mathrm{ppm}$ is the maximum sulfur content of ASTM A36 steel published in the industry standard. And $130 \mathrm{ppm}$ is the sulfur content measured in the literature [22]. Figure 2 shows the change in surface tension with temperature for the three sulfur contents [23]. A three-dimensional transient analysis of GMA welding was also performed to verify the models used. Figure 3 shows the 3D computational domain and the Cartesian mesh used in the simulation. The computational domain near the area where the melting occurred was divided into a minimum mesh size of $0.2 \mathrm{~mm}$ as recommended in the literature [24]. Table 3 shows the boundary conditions of the $3 \mathrm{D}$ domain, which were defined so that the 
Table 1 Boundary conditions for two-dimensional axisymmetric stationary arc welding simulation

\begin{tabular}{lllll}
\hline & $\mathrm{AB}$ & $\mathrm{BC}$ & $\mathrm{CD}$ & $\mathrm{AD}$ \\
\hline$u_{r}$ & 0 & $\frac{\partial u_{r}}{\partial z}=0$ & $\frac{\partial u_{r}}{\partial r}=0$ & $\frac{\partial u_{r}}{\partial z}=0$ \\
$w$ & $\frac{\partial w}{\partial r}=0$ & $\frac{\partial w}{\partial z}=0$ & $\frac{\partial p}{\partial p}$ \\
$p$ & $\frac{\partial p}{\partial r}=0$ & $\frac{\partial p}{\partial r}=0$ & 0 \\
$h$ & $\frac{\partial h}{\partial r}=0$ & $\frac{\partial h}{\partial z}=0$ & $\frac{\partial h}{\partial r}=0$ & $\frac{\partial p}{\partial z}=0$ \\
\hline
\end{tabular}

differential values of all independent variables are 0 (Neumann boundary condition).

The workpiece was a 10-mm-thick structural carbon steel (ASTM A36). The thermophysical properties used in the simulation are shown in Table 4. For the consumable electrode, a stainless steel solid wire (Y308) was used. The reason for using the stainless solid wire is that it is expected to be easy to experimentally analyze the alloying element distribution because the workpiece (A36 steel) has no chromium and nickel contents, whereas the wire (Y308) has high chromium and nickel contents with $20 \%$ and $10 \%$, respectively. Welding conditions used in the simulation were the same as those in the experiment: an arc voltage of $28 \mathrm{~V}$, an arc current of 231 A, a wire feeding rate of $8 \mathrm{~m} / \mathrm{min}$, a welding speed of $1 \mathrm{~m} / \mathrm{min}$, and a torch angle of $61^{\circ}$.

\subsection{Governing equations}

In this study, the basic governing equations - mass conservation, momentum conservation, and energy conservation equation - are used to perform a three-dimensional transient analysis of the heat and mass flow during the arc welding process. In addition, the VOF equation for tracking free surface and additional conservation equations for calculating the alloying element distribution were introduced. Assuming Newtonian fluid and incompressible laminar flow, the governing equations used in this study are as follows.

Table 2 Simulation cases for stationary arc welding

\begin{tabular}{llllllllllll}
\hline Driving force & \multicolumn{1}{ll}{ Case } \\
\cline { 2 - 11 } & A1 & A2 & A3 & A4 & A5 & A6 & A7 & A8 & A9 & A10 \\
\hline Buoyancy & $\mathrm{X}$ & O & X & X & X & X & X & X & X & O \\
Drag & $\mathrm{X}$ & $\mathrm{X}$ & O & X & X & X & X & X & X & O \\
Arc pressure & $\mathrm{X}$ & $\mathrm{X}$ & $\mathrm{X}$ & O & X & X & X & X & X & O \\
Electromagnetic & $\mathrm{X}$ & $\mathrm{X}$ & $\mathrm{X}$ & $\mathrm{X}$ & $\mathrm{O}$ & $\mathrm{X}$ & $\mathrm{X}$ & $\mathrm{X}$ & $\mathrm{X}$ & $\mathrm{O}$ \\
Marangoni & $\mathrm{X}$ & $\mathrm{X}$ & $\mathrm{X}$ & $\mathrm{X}$ & $\mathrm{X}$ & $\mathrm{O}^{1)}$ & $\mathrm{O}^{2)}$ & $\mathrm{O}^{3)}$ & $\mathrm{X}$ & $\mathrm{O}^{1)}$ \\
Droplet & $\mathrm{X}$ & $\mathrm{X}$ & $\mathrm{X}$ & $\mathrm{X}$ & $\mathrm{X}$ & $\mathrm{X}$ & $\mathrm{X}$ & $\mathrm{X}$ & $\mathrm{O}$ & $\mathrm{O}$ \\
\hline
\end{tabular}

1) S: 0 ppm; ${ }^{2)} \mathrm{S}: 130 \mathrm{ppm} ;{ }^{3)} \mathrm{S}: 500 \mathrm{ppm}$
Mass conservation equation:

$\nabla \cdot v=\frac{\dot{m}_{s}}{\rho}$

where, $v$ is the velocity, $\dot{m}_{s}$ is a mass source by molten droplets, and $\rho$ is the density.

Momentum conservation equation:

$\frac{\partial v}{\partial t}+v \cdot \nabla v=-\frac{1}{\rho} \nabla p+\nu \nabla^{2} v-K v+\frac{\dot{m_{s}}}{\rho}\left(v_{s}-v\right)+G$

where, $K=C{\frac{F_{s}^{2}}{\left(1-F_{s}\right)}}^{3}+B$,

where, $p$ is the pressure, $\nu$ is the dynamic viscosity, $K$ is the drag coefficient for the porous media model in the mushy zone, $v_{s}$ is the velocity vector for the mass source, $G$ is the body acceleration by body forces, $C$ is a constant for mushy zone morphology, $F_{s}$ is the solid fraction, and $B$ is a positive zero to prevent being divided by 0 . The third term on the right side of Eq. (2) represents the amount of momentum dissipated by friction in the mushy zone. The mushy zone is a region where the temperature is between the solidus and the liquidus. In this area, the dynamic viscosity and the drag coefficient were calculated using the lever rule. As shown in Fig. 4, the mushy zone is further divided into three regions by the coherent solid fraction (0.15) and the critical solid fraction, $F_{c r}$ (0.67). If the solid fraction is larger than the critical solid fraction, the dynamic viscosity and the drag coefficient are large enough to indicate that there is no fluid flow. If the solid fraction is smaller than the critical solid fraction, the dynamic viscosity is calculated by using the equation $\nu=\nu_{0}\left(1-\underline{F_{s}}\right.$ $\left.F_{c r}\right)^{-1.55}$. The drag coefficient is 0 in the region where the solid fraction is smaller than the coherent solid fraction because the solid crystals, which are sparsely distributed, do not form a coherent solid structure but float freely in the liquid. In the area where the solid fraction is between the coherent solid fraction and the critical solid fraction, the equation presented in (2) is used, which is obtained through the Carman-Kozeny equation derived from the Darcy model by assuming that the mushy zone can be regarded as a porous medium [26].

Energy conservation equation:

$\frac{\partial h}{\partial t}+v \cdot \nabla h=\frac{1}{\rho} \nabla \cdot(k \nabla T)+\dot{h_{s}}$ 
Table 3 Boundary conditions for three-dimensional moving arc welding simulation

\begin{tabular}{|c|c|c|c|c|c|}
\hline & $\mathrm{ABCD}$ & EFGH & DCGH & ABFE & EADH \\
\hline$u$ & $\frac{\partial u}{\partial y}=0$ & $\frac{\partial u}{\partial v}=0$ & $\frac{\partial u}{\partial x}=0$ & $\frac{\partial u}{\partial x}=0$ & $\frac{\partial u}{\partial z}=0$ \\
\hline$v$ & $\frac{\partial v}{\partial y}=0$ & $\frac{\partial v}{\partial y}=0$ & $\frac{\partial v}{\partial x}=0$ & $\frac{\partial v}{\partial x}=0$ & $\frac{\partial v}{\partial z}=0$ \\
\hline$w$ & $\frac{\partial w}{\partial y}=0$ & $\frac{\partial w}{\partial y}=0$ & $\frac{\partial w}{\partial x}=0$ & $\frac{\partial w}{\partial x}=0$ & $\frac{\partial w}{\partial z}=0$ \\
\hline$p$ & $\frac{\partial p}{\partial y}=0$ & $\frac{\partial p}{\partial y}=0$ & $\frac{\partial p}{\partial x}=0$ & $\frac{\partial p}{\partial x}=0$ & $\frac{\partial p}{\partial z}=0$ \\
\hline$h$ & $\frac{\partial h}{\partial y}=0$ & $\frac{\partial h}{\partial y}=0$ & $\frac{\partial h}{\partial x}=0$ & $\frac{\partial h}{\partial x}=0$ & $\frac{\partial h}{\partial z}=0$ \\
\hline
\end{tabular}

where, $h$ is the enthalpy, $k$ is the thermal conductivity, $T$ is the temperature, and $\dot{h_{s}}$ is the enthalpy source term by the mass source. The enthalpy-based continuum model in Eq. (4) was used to consider the phase change between solid and liquid.

$h=\left\{\begin{array}{cc}\rho_{s} C_{s} T & \left(T \leq T_{s}\right) \\ h\left(T_{s}\right)+h_{s l} \frac{T-T_{s}}{T_{l}-T_{s}} & T_{s} \leq T \leq T_{l} \\ h\left(T_{l}\right)+\rho_{l} C_{l}\left(T-T_{l}\right) & \left(T_{l} \leq T\right)\end{array}\right.$

where, $\rho_{s}$ and $\rho_{l}$ are the solid and liquid density, $C_{s}$ and $C_{l}$ are the solid and liquid specific heat, and $T_{s}$ and $T_{l}$ are the solidus and liquidus temperature, respectively. $h_{s l}$ is the latent heat of fusion.

VOF equation:

$\frac{\partial F}{\partial t}+\nabla \cdot(v F)=\dot{F}_{S}$

where, $F$ is the volume of fluid and $\dot{F}_{s}$ is the volume source by the mass source.

Additional conservation equation:

In order to simulate the distribution and behavior of alloying elements over time, the following additional conservation equation was used, which is the common advection equation like the VOF equation.

$\frac{\partial \Phi}{\partial t}+\nabla \cdot(v \Phi)=\dot{\Phi}_{S}$

where, $\Phi$ is the volume fraction of alloying element and $\dot{\Phi}_{S}$ is the source term by the mass source. Here, diffusion effect of the alloying elements was not considered.

\subsection{Boundary conditions}

Energy input due to arc heat flux and energy losses due to convection, radiation, and evaporation imposed on the workpiece. These can be expressed as follows.

$$
\begin{aligned}
q(x, y, z) & =q_{A}-q_{\mathrm{conv}}-q_{\mathrm{rad}}-q_{\mathrm{evap}} \\
& =q_{A}-h\left(T-T_{0}\right)-\varepsilon_{r} \sigma\left(T^{4}-T_{0}^{4}\right)-q_{\mathrm{evap}}
\end{aligned}
$$

where, $q_{A}$ is the arc heat flux, $q_{\text {conv }}$ is the convective heat loss, $q_{\mathrm{rad}}$ is the radiative heat loss, $q_{\text {evap }}$ is the heat loss by evaporation, $h$ is the convective heat transfer coefficient, $T_{0}$ is the ambient temperature, $\varepsilon_{r}$ is the surface radiation emissivity, and $\sigma$ is the Stefan-Boltzmann constant. It was assumed that $18 \%$ of the evaporated material were re-condensed on the surface. The heat fluxes defined in Eq. (7) were applied to the free surface cells using the source term in Eq. (3). On the bottom surface, only convection and radiative heat losses were considered.

The pressure boundary condition on the free surface can be expressed by the pressure balance of arc pressure and surface tension as follows.

$p=p_{A}+\frac{\gamma}{R_{c}}$

where, $p_{A}$ is the arc pressure, $\gamma$ is the surface tension, and $R_{c}$ is the surface curvature.

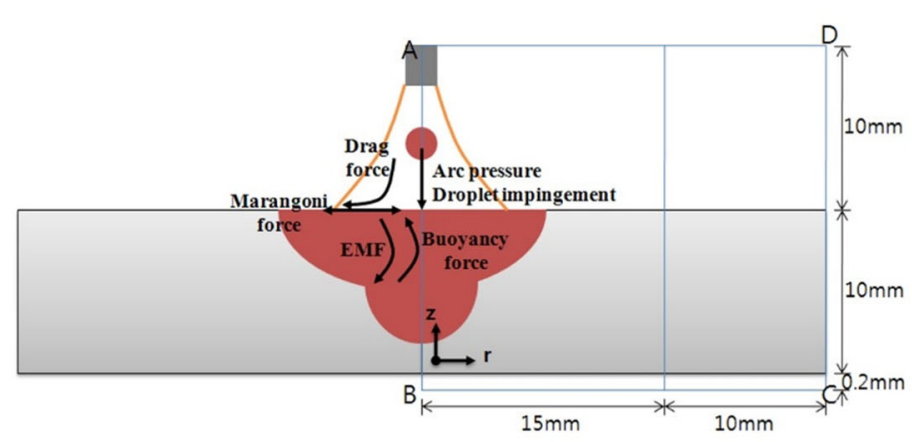

(a)

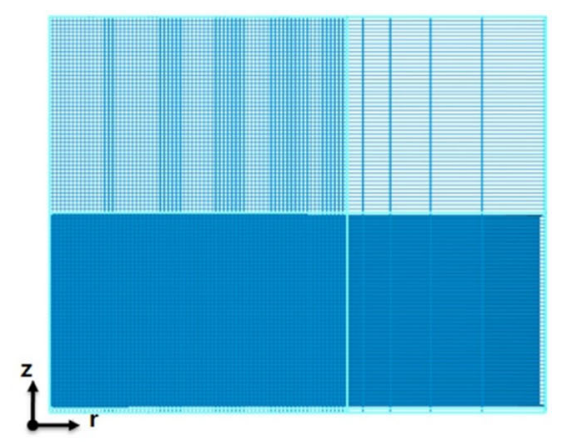

(b)

Fig. 1 a, b Schematic diagram of solution domain and mesh for axisymmetric stationary arc welding simulation 


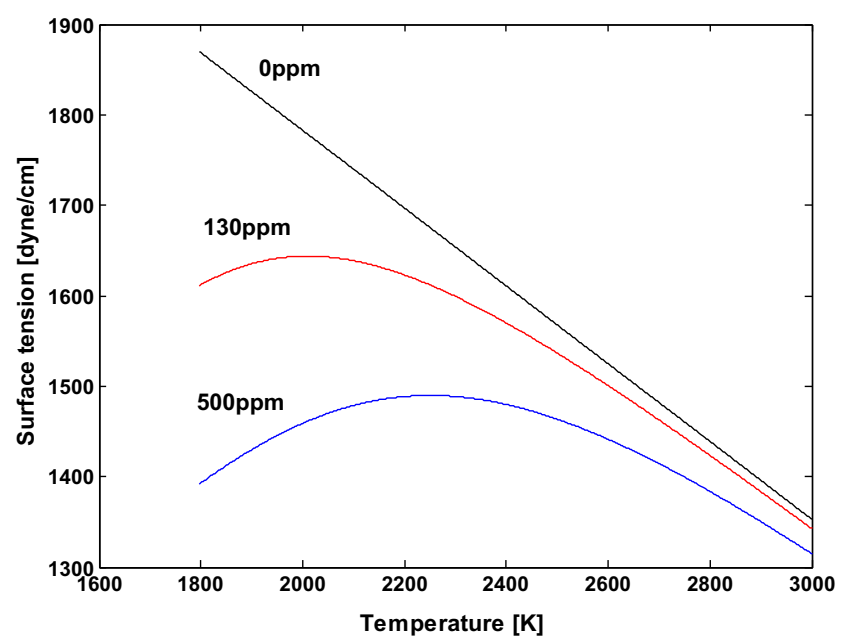

Fig. 2 Surface tension vs. temperature for an Fe-S system containing different amounts of sulfur [23]

\subsection{Mathematical models for arc welding}

\subsubsection{Arc heat source and droplet generation}

In this study, the arc heat source was modeled with the Gaussian surface heat flux.

$\eta_{A} q_{A}(x, y)=\eta_{A} \frac{V I}{2 \pi r_{A}^{2}} \exp \left(-\frac{x^{2}+y^{2}}{2 r_{A}^{2}}\right)$

where, $\eta_{A}$ is the arc efficiency, $V$ is the arc voltage, $I$ is the arc current, and $r_{A}$ is the effective radius of the arc heat source. In GMA welding, the overall efficiency is expressed as the sum of the arc efficiency and the droplet generation efficiency. In this study, droplets were generated at the frequency, $f_{d}$, which can be calculated using Eq. (10). The droplet temperature was $2400 \mathrm{~K}$, and the droplet radius, $r_{d}$, was equal to the electrode radius, $r_{w}$.

$f_{d}=\frac{5 r_{w}{ }^{2} \mathrm{WFR}}{4 r_{d}{ }^{3}}(\mathrm{~Hz})$

where, WFR is the wire feeding rate.
The droplet generation efficiency can be calculated as follows.

$\eta_{d}=\frac{4}{3 V I} \pi r_{d}{ }^{3} \rho\left[C_{s}\left(T_{s}-T_{0}\right)+C_{l}\left(T_{d}-T_{s}\right)+h_{s l}\right] f_{d}$

Therefore, assuming that the overall efficiency of the GMA welding is $80 \%$, the arc efficiency can be calculated as follows.

$\eta_{A}=0.8-\eta_{d}$

\subsubsection{Arc pressure, Marangoni force, and drag force}

Of the driving forces generated in arc welding, the surface forces include arc pressure, Marangoni force, and drag force. The arc pressure was applied by using the following Gaussian function [27].

$P_{A}(x, y)=\frac{F}{2 \pi r_{A}^{2}} \exp \left(-\frac{x^{2}+y^{2}}{2 r_{A}^{2}}\right)$

where, $F$ is the total arc force.

The molten pool surface is subjected to shear force by the temperature and the surface active element, causing a flow called the Marangoni flow. The following equation was used to account for the change in surface tension according to the temperature and the active element [28].

$\gamma(T)=\gamma_{m}^{o}-A\left(T-T_{m}\right)-R T \Gamma_{s} \ln \left(1+k_{1} a_{i} e^{-\Delta H^{o} / R T}\right)$

where, $\gamma_{m}^{o}$ is the surface tension of pure metal at the melting temperature, $A$ is the surface tension gradient of pure metal, $T_{m}$ is the melting temperature, $\Gamma_{s}$ is the surface excess at saturation, $k_{1}$ is the constant related to the entropy of segregation, $a_{i}$ is the thermodynamic activity of component, and $\Delta H^{\circ}$ is the standard heat of adsorption.

The drag force is generated by the arc plasma jet colliding with the molten pool surface and spreading from the center. The following analytical solution for the shear stress that occurs when the jet impinges perpendicular to a flat surface was

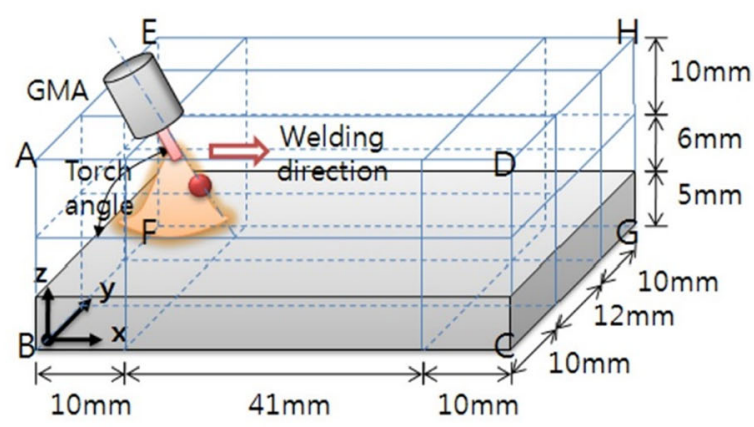

(a)

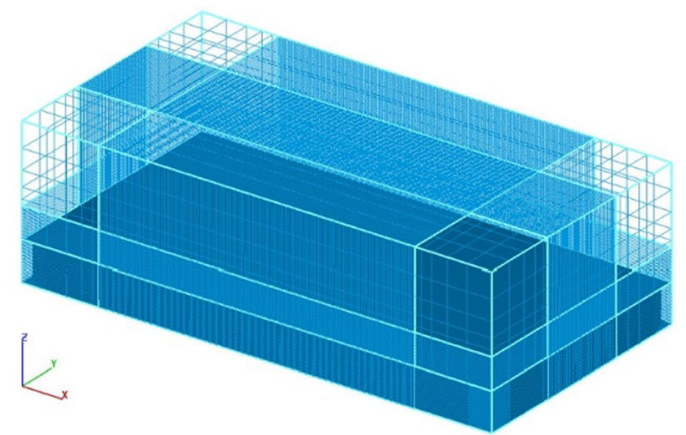

(b)

Fig. 3 a, b Schematic diagram of solution domain and mesh for three-dimensional moving arc welding simulation 
Table 4 Thermophysical material properties of materials used in simulation

\begin{tabular}{lll}
\hline Properties & Symbol & Value \\
\hline Density & $\rho$ & 7.8 (solid), 6.9 (liquid) $\mathrm{g} / \mathrm{cm}^{3}$ \\
Thermal conductivity & $k$ & Temperature-dependent [25] erg/cm K s \\
Dynamic viscosity at melting point & $\nu_{0}$ & $5.9 \times 10^{-2} \mathrm{~g} / \mathrm{cm} \mathrm{s}^{3}$ \\
Surface tension & $\gamma$ & $1897 \mathrm{dyne} / \mathrm{cm}$ \\
Surface tension gradient & $\partial \gamma / \partial T$ & $-0.43 \mathrm{dyne} / \mathrm{cm} \mathrm{K}$ \\
Specific heat of solid & $C_{s}$ & $7.26 \times 10^{6} \mathrm{erg} / \mathrm{g} \mathrm{s} \mathrm{K}$ \\
Specific heat of liquid & $C_{l}$ & $7.32 \times 10^{6} \mathrm{erg} / \mathrm{g} \mathrm{s} \mathrm{K}$ \\
Latent heat of fusion & $h_{s l}$ & $2.77 \times 10^{9} \mathrm{erg} / \mathrm{g} \mathrm{s}$ \\
Latent heat of vaporization & $h_{v}$ & $7.34 \times 10^{10} \mathrm{erg} / \mathrm{g} \mathrm{s}$ \\
Coefficient of thermal expansion & $\beta$ & $1.0 \times 10^{-5} \mathrm{~cm} / \mathrm{cm} \mathrm{K}^{\circ}$ \\
Liquidus temperature & $T_{l}$ & $1798 \mathrm{~K}$ \\
Solidus temperature & $T_{s}$ & $1768 \mathrm{~K}$ \\
Boiling temperature & $T_{b}$ & $2900 \mathrm{~K}$ \\
Convection heat transfer coefficient & $h$ & $2.0 \times 10^{4}$ (free) $1.0 \times 10^{5}$ (forced) erg/cm ${ }^{2} \mathrm{~s} \mathrm{~K}$ \\
Emissivity & $\varepsilon$ & 0.4
\end{tabular}

used in simulation [29].

$\frac{\tau}{\rho_{p} u_{0}^{2}} \operatorname{Re}_{0}^{1 / 2}\left(\frac{H}{D}\right)^{2}=g_{2}\left(\frac{r}{H}\right)$

where, $\tau$ is the shear stress, $\rho_{p}$ is the plasma density, $u_{0}$ is the initial velocity, $R e_{0}$ is the Reynolds number, $H$ is the nozzle height, $D$ is the nozzle diameter, $r$ is the radius, and $g_{2}$ is the universal function. For the arc plasma jet, $H$ and $D$ were assumed to be the arc length and the electrode diameter, respectively.

\subsubsection{Electromagnetic force and buoyancy force}

Of the driving forces generated in arc welding, the body forces include electromagnetic force and buoyancy force.
The radial and vertical components of electromagnetic force were calculated using the analytical solution by Kou and Sun as follows [30].

$$
\begin{aligned}
& F_{r}=-J_{z} B_{\theta} \\
& F_{z}=J_{r} B_{\theta}
\end{aligned}
$$

where,

$$
\begin{aligned}
& J_{z}=\frac{I}{2 \pi} \int_{0}^{\infty} \lambda J_{0}(\lambda r) \exp \left(-\lambda^{2} r_{A}{ }^{2} / 12\right) \frac{\sin h[\lambda(c-z)]}{\sin h(\lambda c)} d \lambda \\
& J_{r}=\frac{I}{2 \pi} \int_{0}^{\infty} \lambda J_{1}(\lambda r) \exp \left(-\lambda^{2} r_{A}^{2} / 12\right) \frac{\cos h[\lambda(c-z)]}{\sin h(\lambda c)} d \lambda \\
& B_{\theta}=\frac{\mu_{m} I}{2 \pi} \int_{0}^{\infty} J_{1}(\lambda r) \exp \left(-\lambda^{2} r_{A}^{2} / 12\right) \frac{\sin h[\lambda(c-z)]}{\sin h(\lambda c)} d \lambda
\end{aligned}
$$

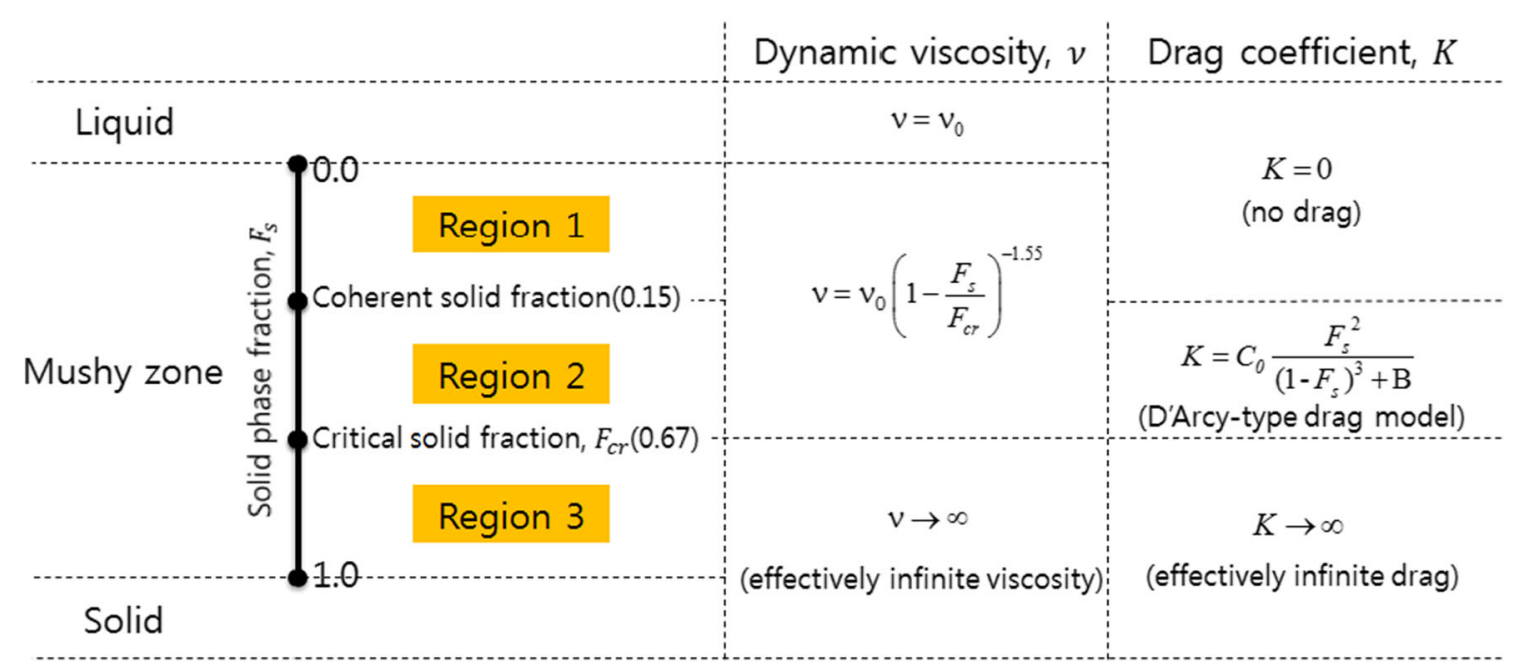

Fig. 4 Dynamic viscosity and drag coefficient in the mushy zone 


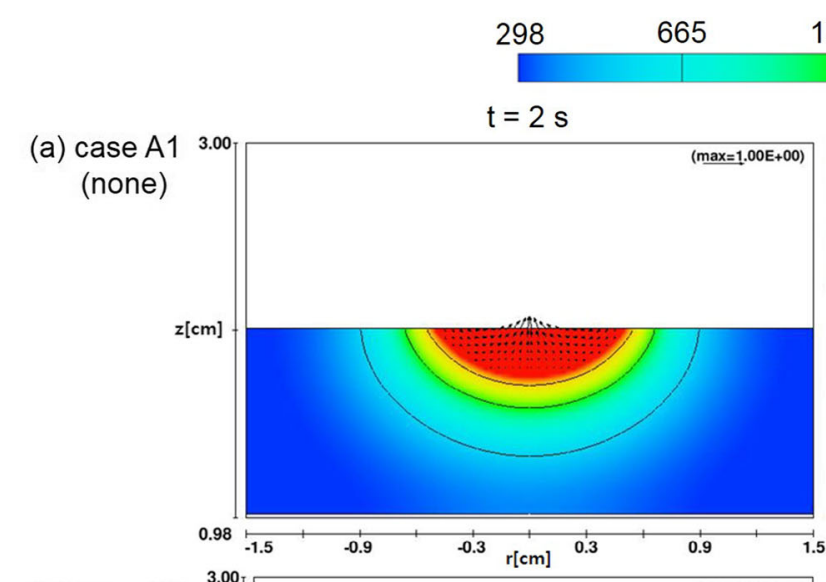

033

1400

1768 temp

(b) case A2

(buoyancy)
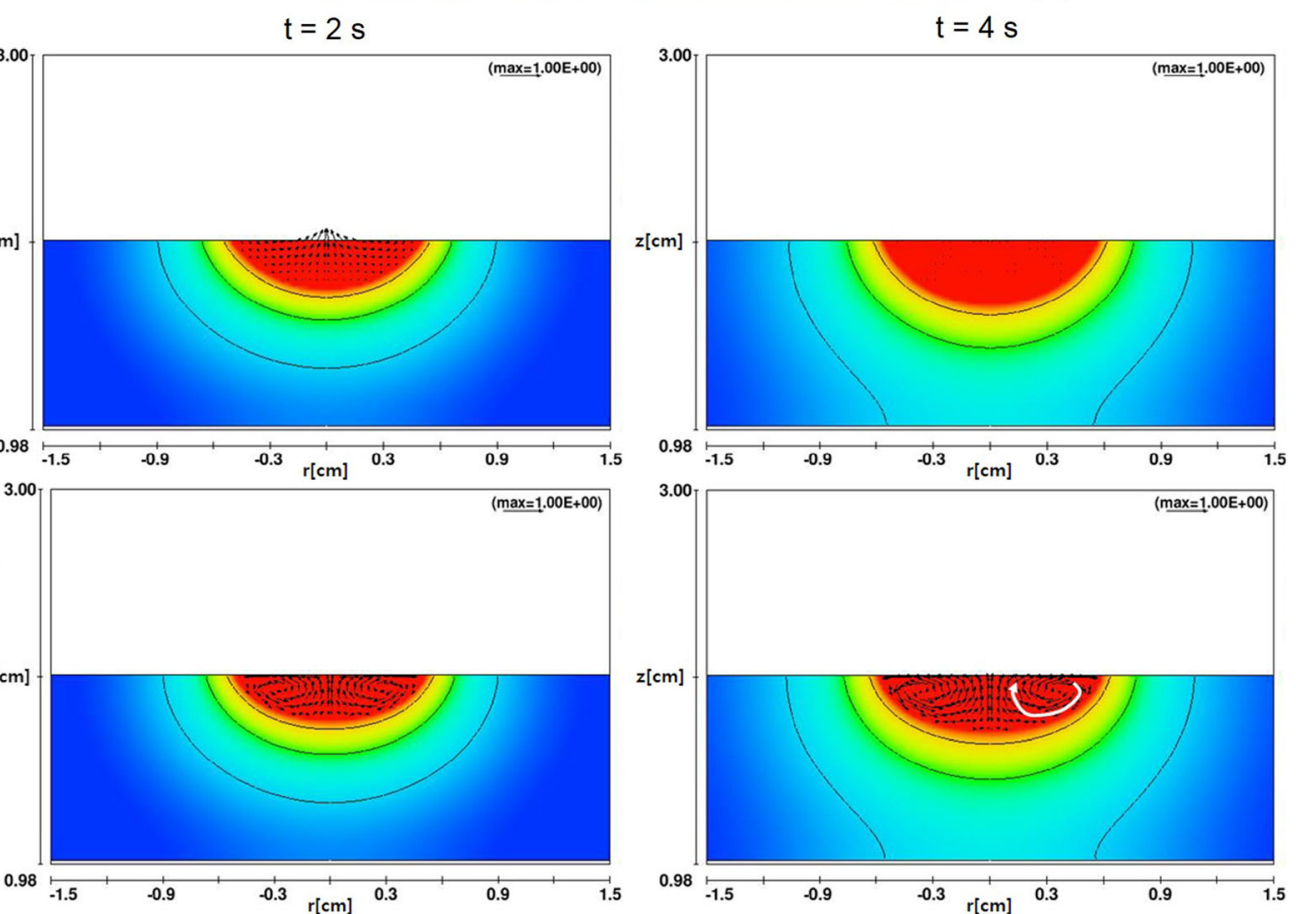

(c) case A3

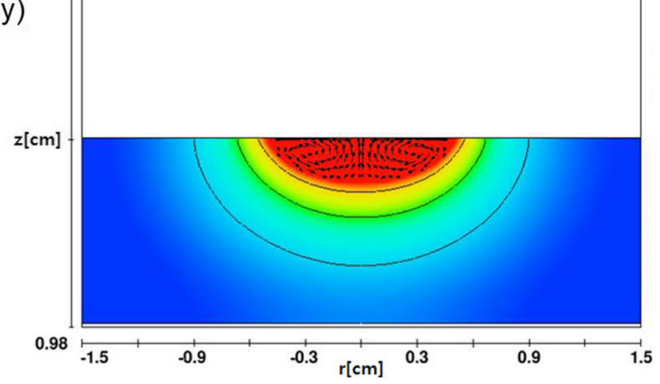

(drag)
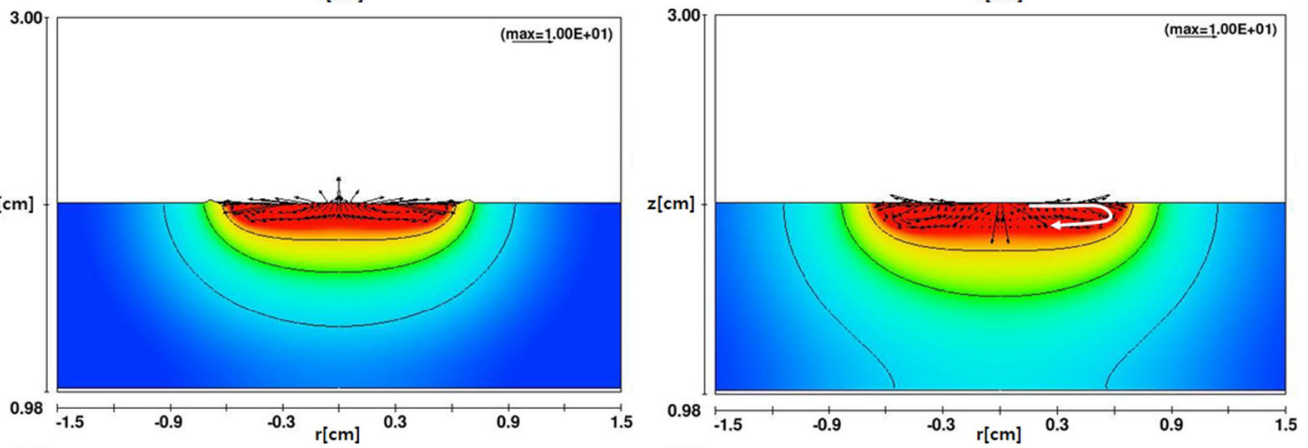

(d) case A4

3.00

(arc pressure)
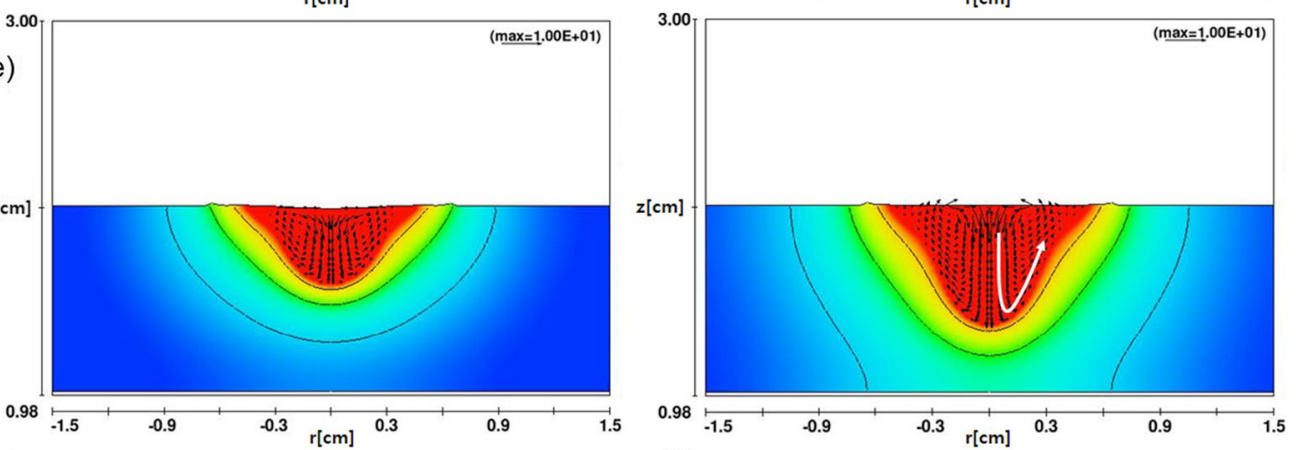

(e) case A5

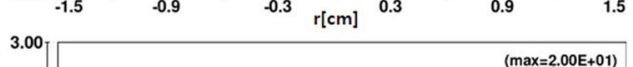

(EMF)
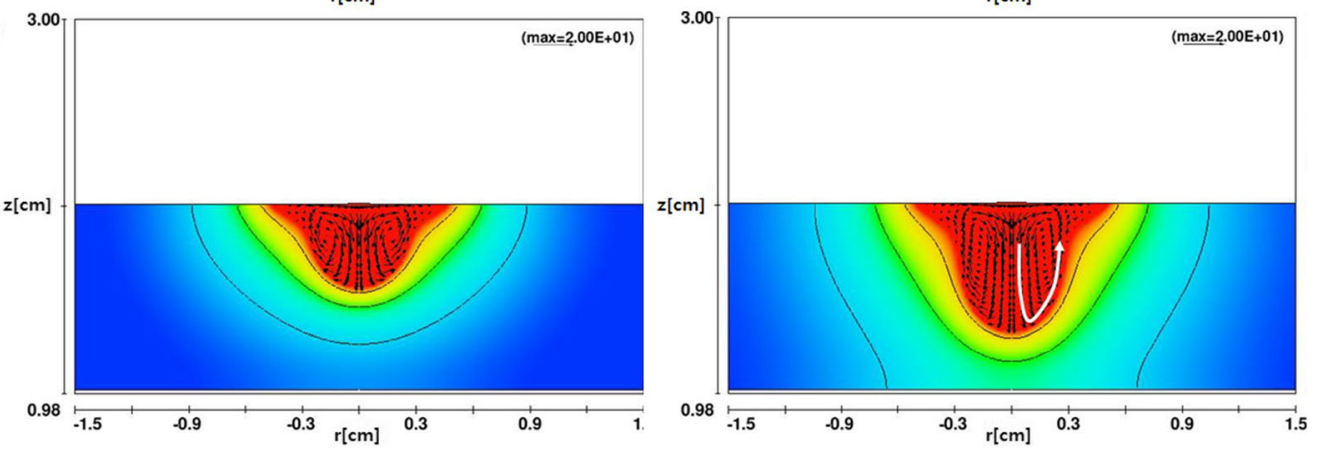

Fig. 5 a-j Temperature profile and molten pool flow in stationary arc spot welding simulation 

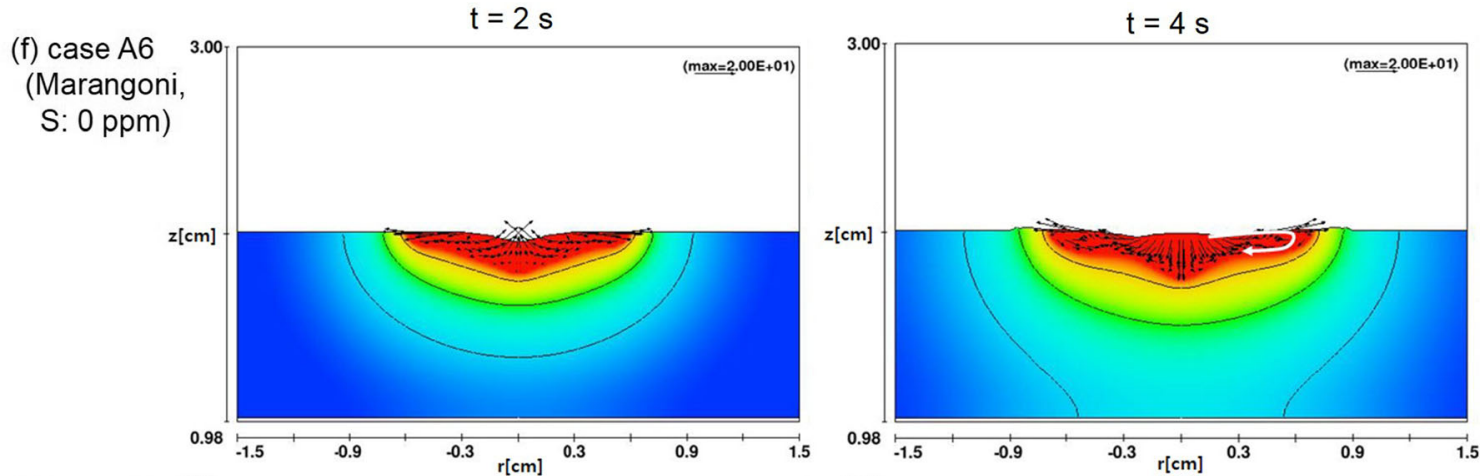

(g) case A7

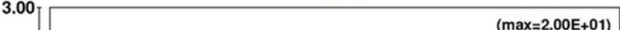

(Marangoni,

S: $130 \mathrm{ppm})$
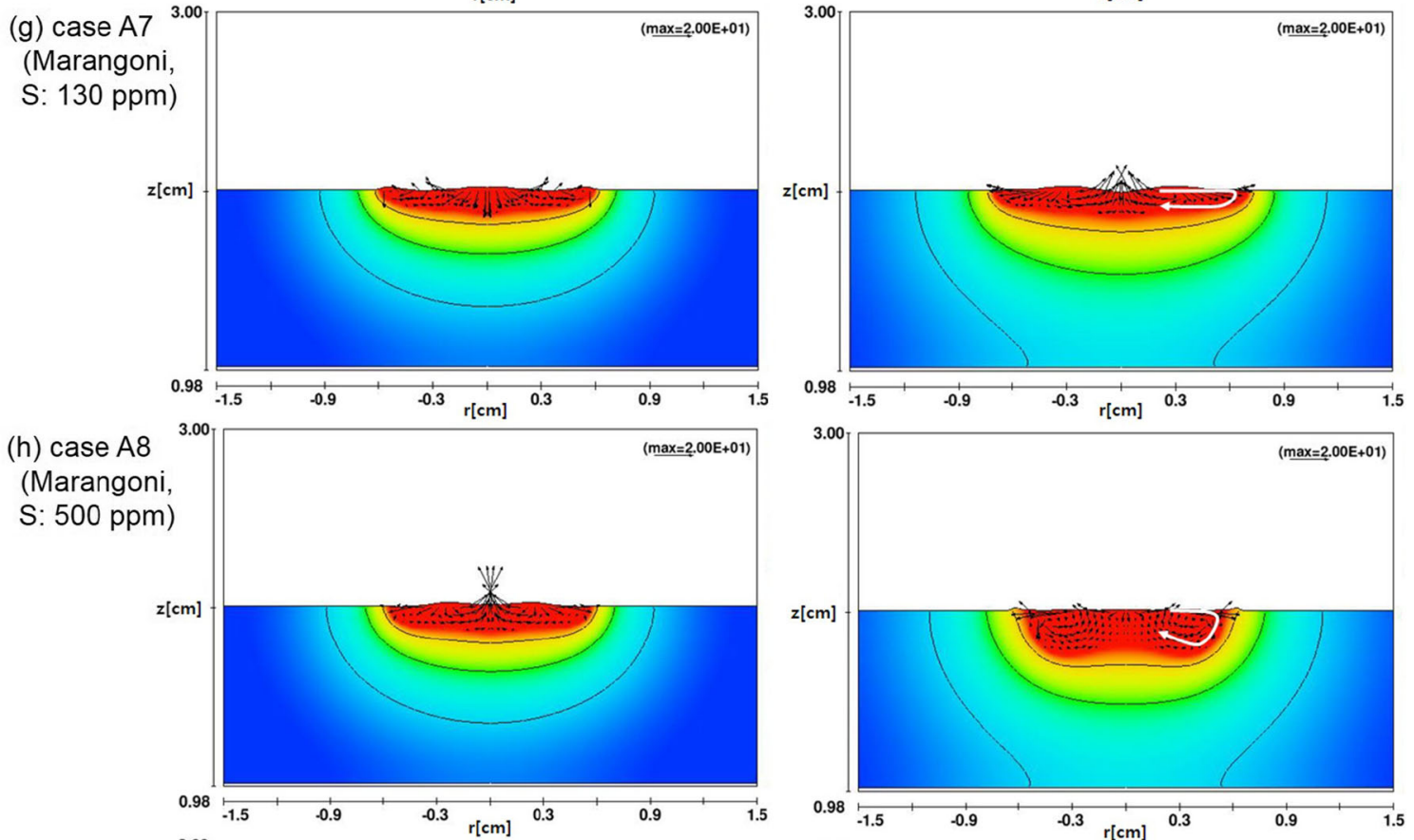

(i) case A9

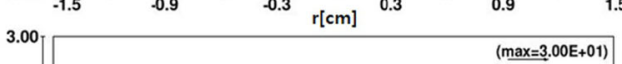

(droplet)

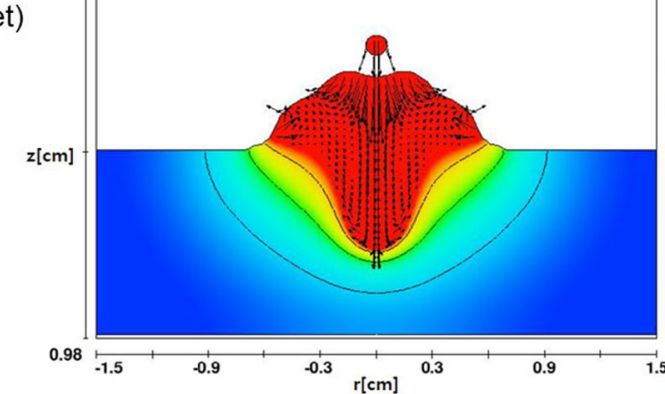

(j) case $A 10^{3}$

(all)

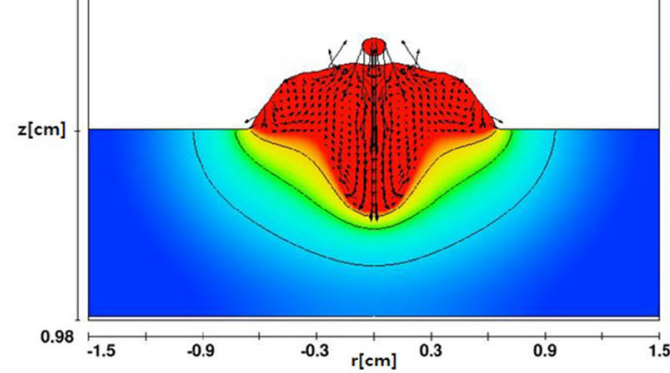

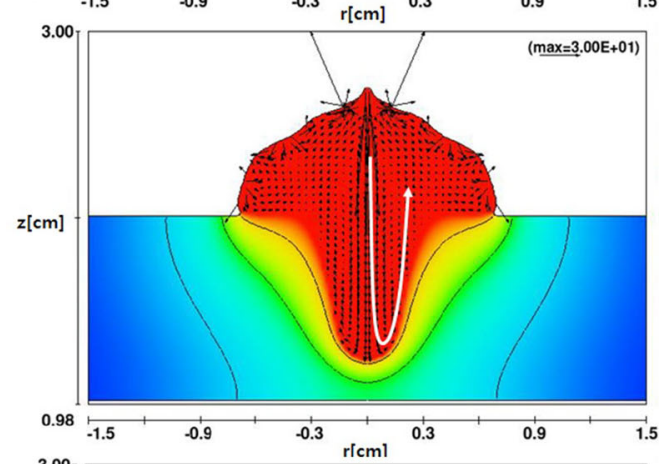

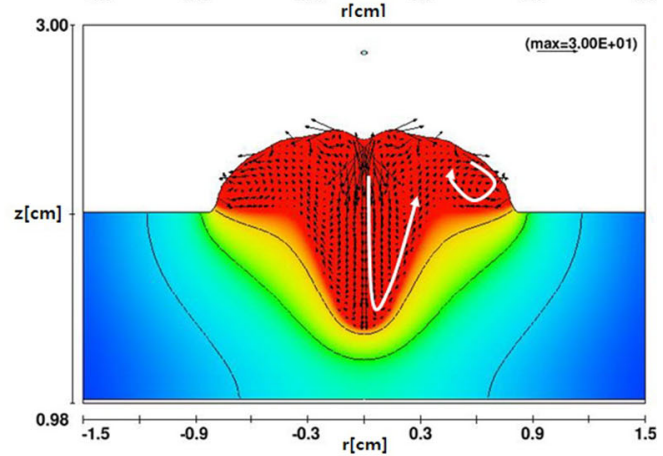

Fig. 5 (continued) 
Fig. 6 Average of maximum velocities with respect to driving force $(2-4 s)$

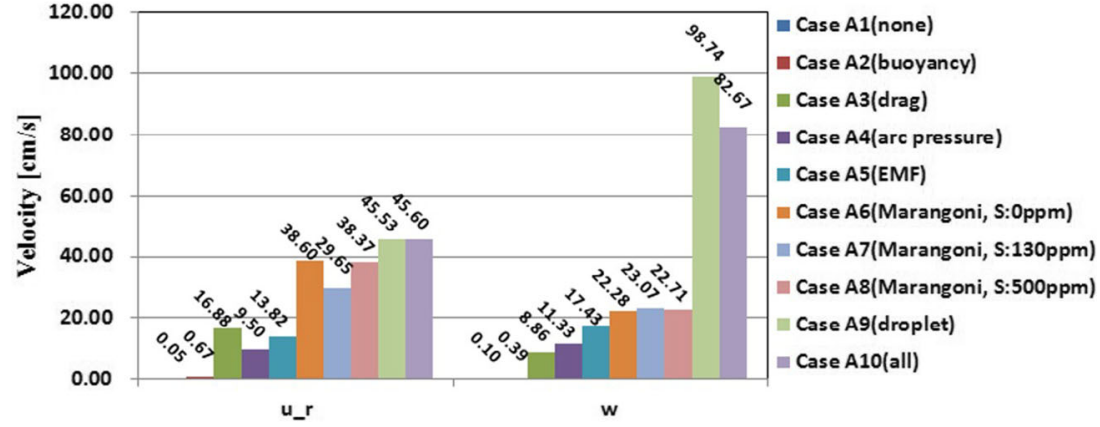

where, $J_{z}$ and $J_{r}$ are the vertical and radial components of the current density, respectively. $B_{\theta}$ is the angular magnetic field. $J_{0}$ and $J_{1}$ are the first kinds of Bessel function of zero order and the first order, respectively. $c$ is the thickness of the workpiece, $z$ is the vertical distance, and $\mu_{m}$ is the magnetic permeability.

Buoyancy is caused by a change in the density of the molten pool. Since it is difficult to know the density change of steel at temperature above the melting point, the coefficient of thermal expansion was used to indirectly account for the density change due to the temperature difference by the Boussinesq approximation.
$F_{b}=\rho g \beta\left(T-T_{0}\right)$

where, $\beta$ is the coefficient of thermal expansion.

\section{Results and discussion}

Figure 5 shows the simulation results for the cases in Table 2. As shown in Fig. 5a, the case with no driving force formed a semi-circular molten pool with a negligible flow. Figure $5 \mathrm{~b}$ shows the simulation result considering only buoyancy. The

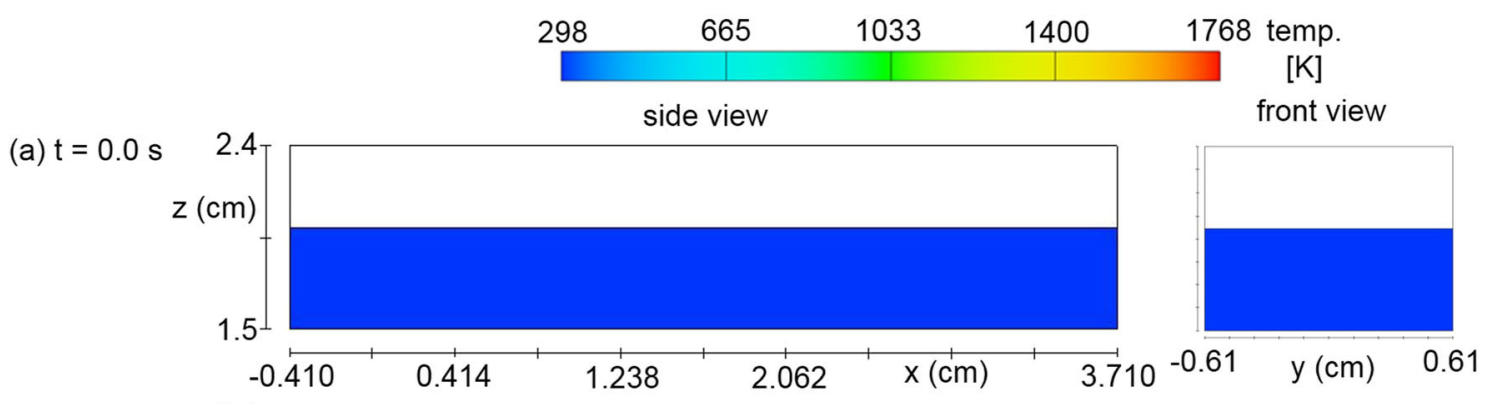

(b) $t=0.6 \mathrm{~s}$
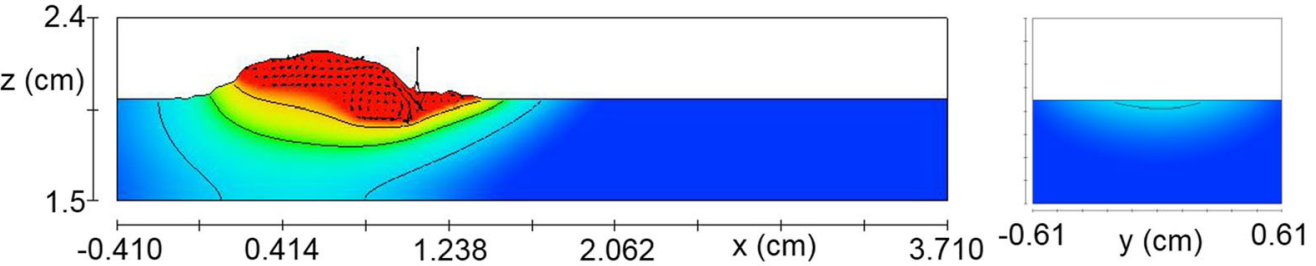

(c) $\mathrm{t}=1.2 \mathrm{~s}$
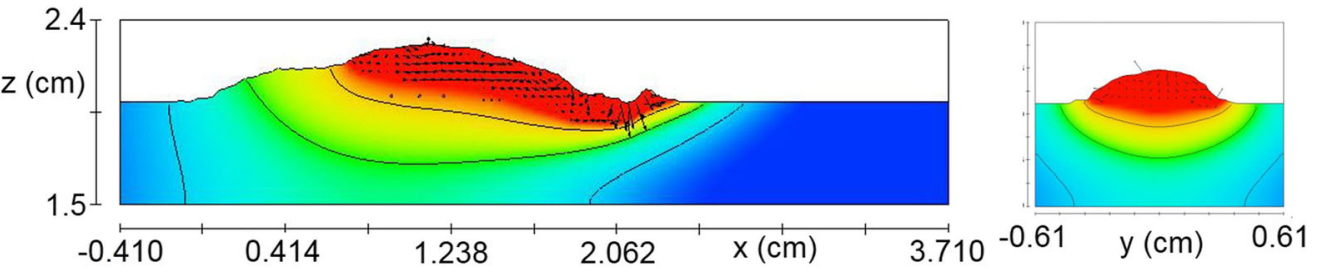

(d) $\mathrm{t}=1.9 \mathrm{~s}$
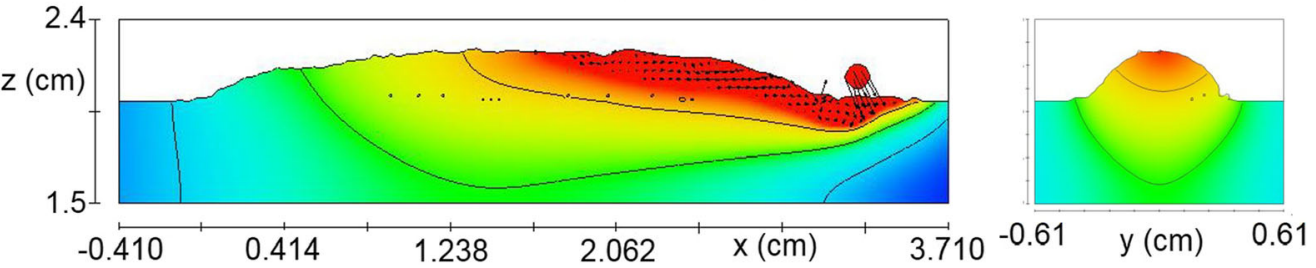

Fig. 7 a-d Simulation results of temperature views over time in GMA welding 


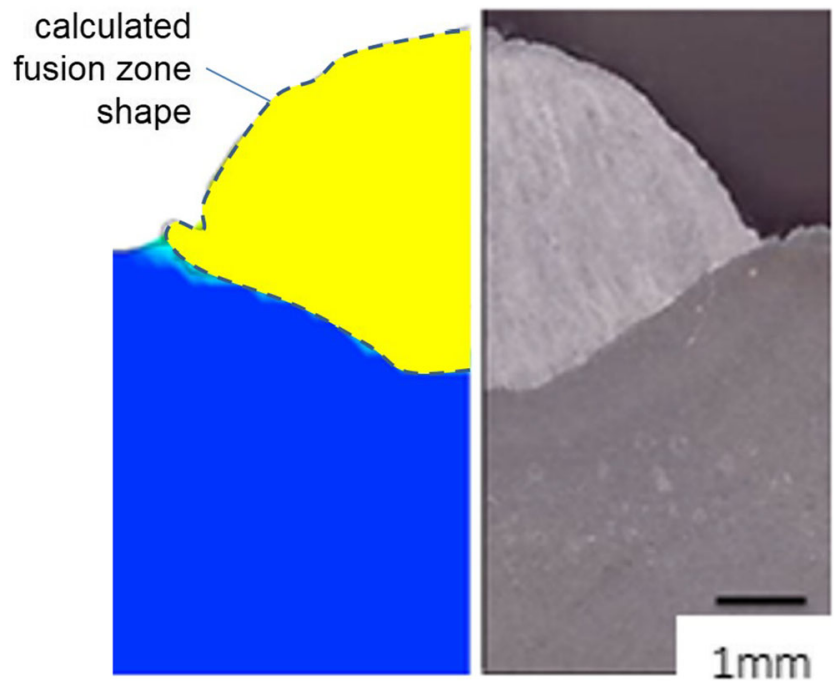

Fig. 8 Comparison of the numerical and experimental fusion zone shape in GMA welding

clockwise-rotating pattern was observed in the molten pool, but the molten pool shape was similar to the shape in Fig. $5 \mathrm{a}$ because the flow was also quite small. Figure $5 \mathrm{c}$ shows the result for the case considering only the drag generated by the arc plasma jet colliding with the molten pool surface, in which a flow pattern spreading in the radial direction was observed. This flow was large enough to change the molten pool shape, resulting in a wider, shallower molten pool compared to the shapes in Fig. 5a and b. Figure 5d shows the simulation result considering only the arc pressure. Due to a strong downward flow generated, a deep molten pool was formed. As shown in Fig. 5e, the case considering only the electromagnetic force also showed a deep penetration together with a similar flow pattern rotating in a counterclockwise direction. Figure $5 \mathrm{f}-\mathrm{h}$ shows the simulation results considering only the Marangoni force for the cases with sulfur contents of $0 \mathrm{ppm}, 130 \mathrm{ppm}$, and 500 ppm. As shown in Fig. 2, as the sulfur content increases, the surface tension decreases, and the region with a positive surface tension gradient increases. The negative surface tension gradient causes surface flows from the center to the outside, resulting in a wide, shallow molten pool, whereas the positive gradient forms a narrow, deep molten pool by generating surface flows from the outside to the center. The simulation results also showed that as the sulfur content increased, the width of the molten pool decreased, and the depth increased. Figure 5i shows the simulation result considering only the droplet impingement. The droplet was spherical with

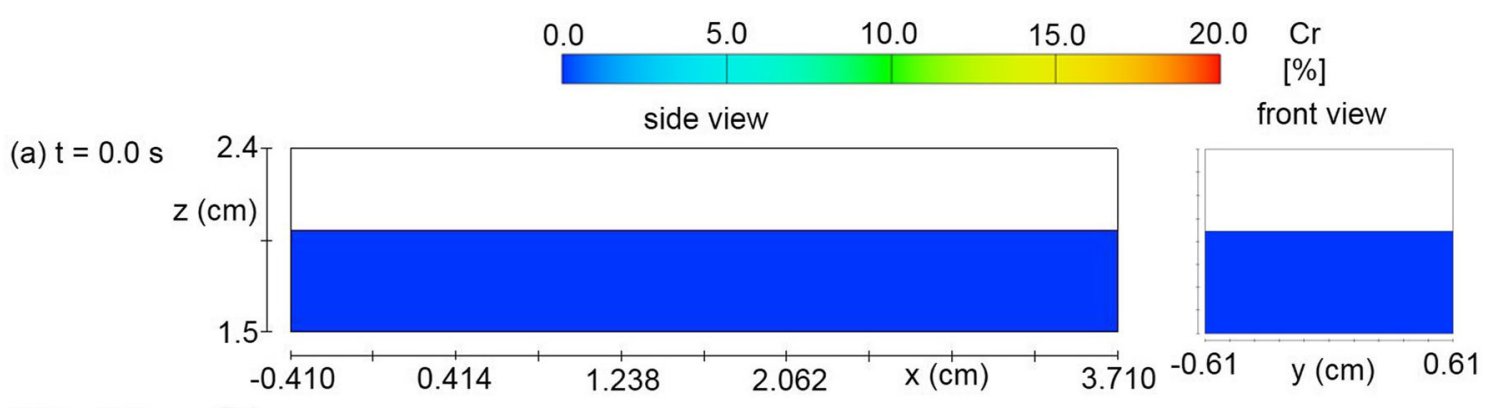

(b) $t=0.6 s$
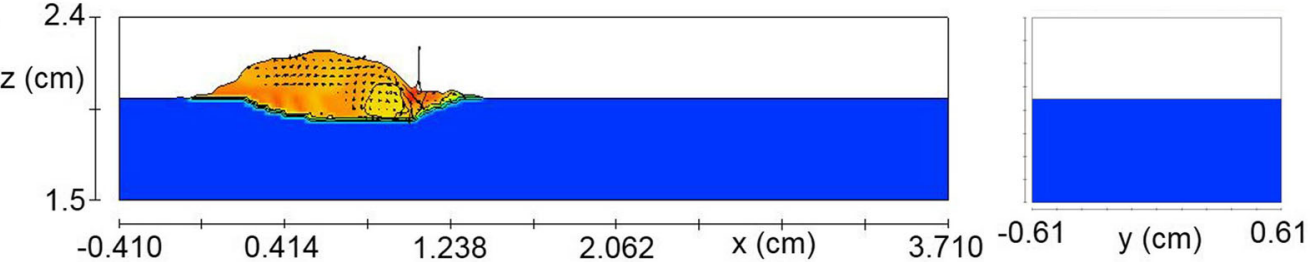

(c) $\mathrm{t}=1.2 \mathrm{~s}$
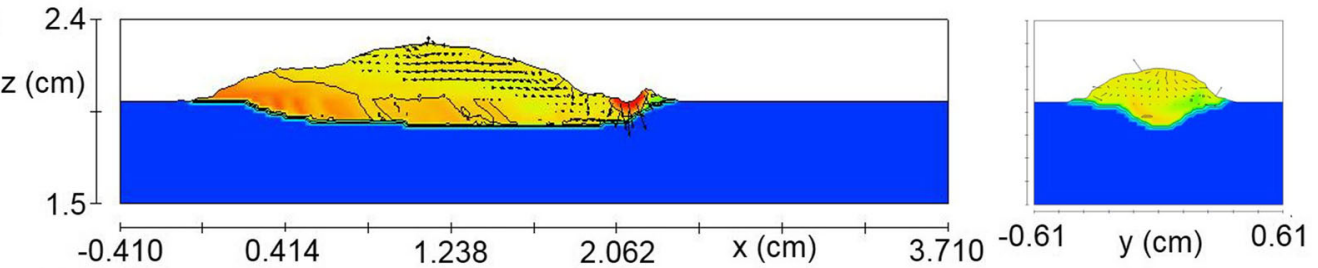

(d) $\mathrm{t}=1.9 \mathrm{~s}$
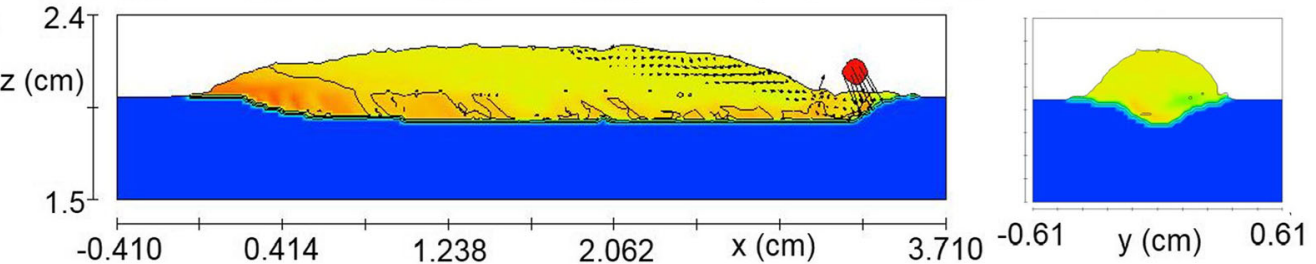

Fig. 9 a-d Simulation results of alloying element $(\mathrm{Cr})$ views over time in GMA welding 

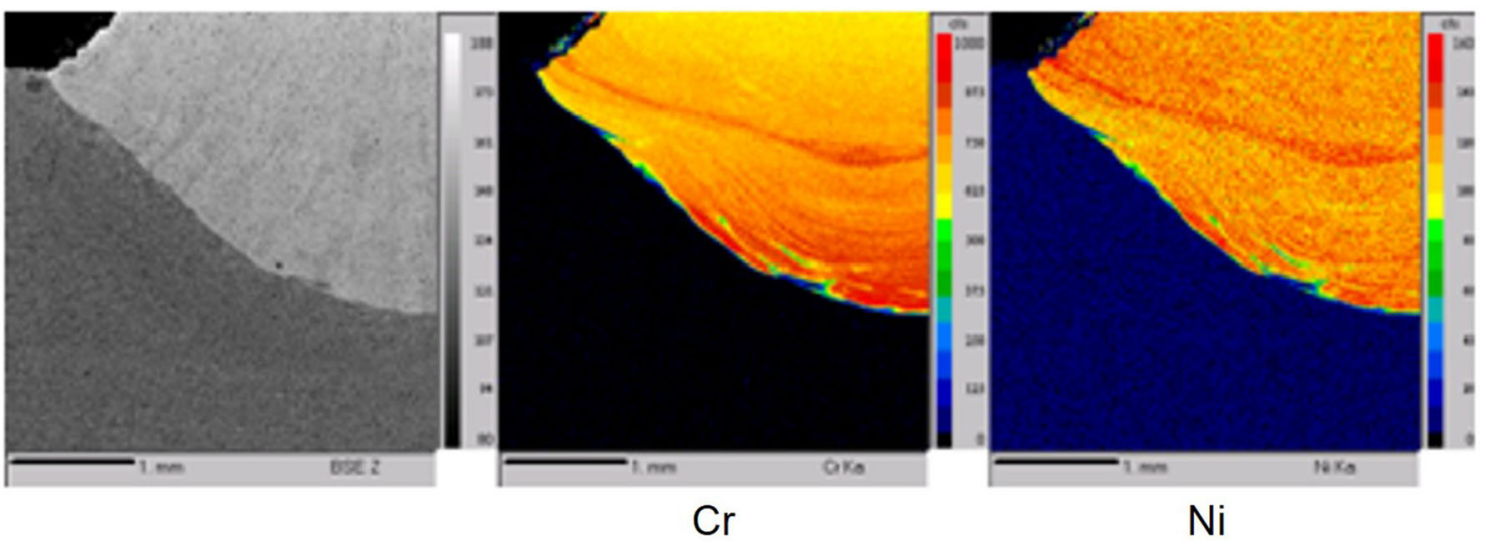

Fig. 10 Measured alloying element distributions in GMA welding

the same radius as that of the solid wire, and the droplet generation frequency was calculated using the wire feeding speed as shown in Eq. (10). The droplet temperature was $2400 \mathrm{~K}$ and the speed was $35 \mathrm{~cm} / \mathrm{s}$ in the -z-direction. Due to the large downward flow by the impingement, the molten pool was deepest among the simulation cases. Figure $5 \mathrm{j}$ shows the simulation result considering all the driving forces mentioned. What is unique about this case compared to the result in Fig. $5 \mathrm{i}$ is that the depth is shallower, and the width is wider due to the interaction of the driving forces. Of the driving forces, buoyancy, drag, and Marangoni forces tended to create a wide and shallow molten pool, whereas electromagnetic force, arc pressure, and droplet impingement created a deep molten pool. Figure 6 shows the average values of the maximum velocities in the molten pool of each case measured from 2 to $4 \mathrm{~s}$ with a period of $0.01 \mathrm{~s}$.

For the radial velocity component, the results are as follows:

- Buoyancy $\ll$ arc pressure $<$ EMF $<$ drag $<$ Marangoni $<$ droplet.

For the vertical velocity component, the results are as follows:

- Buoyancy $\ll$ drag $<$ arc pressure $<$ EMF $<$ Marangoni $\ll$ droplet.

From the above results, the buoyancy is negligible compared to other driving forces, so it is not necessary to consider it in the simulation of GMA welding. On the other hand, the droplet impingement is the most important driving force that determines maximum velocity values not only in radial but also in axial direction. Especially it is the dominant factor that determines penetration depth. The next most effective driving force is the Marangoni force, which increases the molten pool width in the sulfur content range considered in this study. Therefore, the interaction between the droplet impingement and the Marangoni force makes the penetration depth in Fig. 5 j smaller compared to Fig. $5 \mathrm{i}$.

Figure 7 shows the temperature distribution of $3 \mathrm{D}$ transient simulation of GMA welding considering all the driving forces mentioned. In the side view, the droplet was generated and transferred according to the set conditions. The droplet collided made a concave molten pool surface in which the molten pool was deepest. Therefore, it is thought that the droplet impingement is dominant to determine the molten pool depth in moving arc welding. Since the downward flow was blocked at the solid-liquid interface, the flow rolled up in the opposite of the welding direction. Due to this flow, the molten pool with the high temperature generated by the droplet and arc flux was pushed backward, and thus the cooling at the molten pool tail was slow, forming an elongated molten pool. In the front view, cooling occurred from the bottom up, and the flow was directed from top to bottom at the molten pool near the droplet impingement, but afterwards the flow mainly occurred from bottom to top. In Fig. 8, the shapes of the fusion zone obtained from the simulation and the experiment were compared. In the simulation, the bead height was $0.23 \mathrm{~cm}$, the width was $0.66 \mathrm{~cm}$, and the penetration depth was $0.13 \mathrm{~cm}$. In the experiment, the height was $0.23 \mathrm{~cm}$, the width was 0.62 $\mathrm{cm}$, and the depth was $0.16 \mathrm{~cm}$. It showed that the mathematical models used in this study were appropriate for simulating the GMA welding.

As shown in Fig. 9, the behavior and distribution of chromium in the molten pool were calculated using the additional conservation equation described in Eq. (6). The distribution of nickel was the same as that of chromium, except that the value was only a half. This was because the diffusion effect was not considered, and both chromium and nickel were determined by the same molten pool flow. Similar results were also seen in the experimental results in Fig. 10. The boundary shape of the fusion zone and the chromium and nickel distribution were the same, and the chromium and nickel distributions had different absolute values, but they had a similar distribution pattern. The results show that when calculating the behavior and 
distribution of chromium and nickel, only the flow can be considered ignoring the diffusion effect as in Eq. (6). In addition, it was found that the alloy element distribution was higher at the bottom, which is considered to be because the alloy elements supplied by droplets reached the bottom due to the high vertical velocity, but they were partially trapped at the solid-liquid interface.

\section{Conclusions}

Heat and mass transfer in GMA welding could be calculated using the welding models validated. The impact of driving forces on the molten pool was analyzed using the simulation results. The following conclusions can be drawn:

- For the welding conditions considered in this study, the effect of driving forces on the molten pool analyzed using the radial and vertical velocity components obtained from the simulation results is as follows.

- For the radial velocity component: Buoyancy « arc pressure $<$ EMF $<$ drag $<$ Marangoni $<$ droplet.

- For the vertical velocity component: Buoyancy « drag $<$ arc pressure $<$ EMF $<$ Marangoni $\ll$ droplet.

- The effect of droplet impingement is absolute in determining the penetration depth. The Marangoni force is less effective, but it can reduce the depth and increase the width to some extent.

- The distribution of alloying elements $(\mathrm{Cr}$ and $\mathrm{Ni})$ is determined by the molten pool flow, and the diffusion effect is negligible. Due to the predominant effect of droplet impingement on the vertical velocity of the molten pool, the element contents are higher at the bottom.

Acknowledgements This paper contains a part of the contents in the author's Ph.D. dissertation [31].

Funding Open Access funding enabled and organized by Projekt DEAL.

\section{Declarations}

Conflict of interest The authors declare no competing interests.

Open Access This article is licensed under a Creative Commons Attribution 4.0 International License, which permits use, sharing, adaptation, distribution and reproduction in any medium or format, as long as you give appropriate credit to the original author(s) and the source, provide a link to the Creative Commons licence, and indicate if changes were made. The images or other third party material in this article are included in the article's Creative Commons licence, unless indicated otherwise in a credit line to the material. If material is not included in the article's Creative Commons licence and your intended use is not permitted by statutory regulation or exceeds the permitted use, you will need to obtain permission directly from the copyright holder. To view a copy of this licence, visit http://creativecommons.org/licenses/by/4.0/.

\section{References}

1. Masubuchi K (1980) Analysis of welded structures: residual stresses, distortion, and their consequences. Pergamon Press, New York

2. Rosenthal D (1946) The theory of moving source of heat and its application to metal treatment. Transactions ASME 43(11):849866

3. Zubairuddin M, Albert SK, Vasudevan M, Mahadevan S, Chaudhari V, Suri VK (2017) Numerical simulation of multi-pass GTA welding of grade 91 steel. J. Manuf. Process. 27:87-97

4. Kim SD, Na SJ (1989) A study on heat and mass flow in stationary gas tungsten arc welding using the numerical mapping method. Proc. Inst. Mech. Eng. Part B-J. Eng. Manuf. 203(4):233-242

5. Kim SD, Na SJ (1992) Effect of weld pool deformation on weld penetration in stationary gas tungsten arc welding. Weld. J. 74(5): $141 \mathrm{~s}-152 \mathrm{~s}$

6. Kim JW, Na SJ (1994) A study on the three-dimensional analysis of heat and fluid flow in gas metal arc welding using boundary-fitted coordinates. J. Eng. Ind. 116(1):78-85

7. Kim JW, Na SJ (1995) A study on the effect of contact tube-toworkpiece distance on weld pool shape in gas metal arc welding. Weld. J. 74(5):141s-152s

8. Lee SY, Na SJ (1995) Analysis of TIG welding arc using boundaryfitted coordinates. Proc. Inst. Mech. Eng. B J. Eng. Manuf. 209(2): $153-164$

9. Lee SY, Na SJ (1996) A numerical analysis of a stationary gas tungsten welding arc considering various electrode angles. Weld. J. 75(9):269s-279s

10. Kim WH, Fan HG, Na SJ (1997) A mathematical model of gas tungsten arc welding considering the cathode and the free surface of the weld pool. Metall. Mater. Trans. B 28:679-686

11. Kim WH, Na SJ (1998) Heat and fluid flow in pulsed current GTA weld pool. Int. J. Heat Mass Transf. 41:3213-3227

12. Kim IS, Basu A (1998) A mathematical model of heat transfer and fluid flow in the gas metal arc welding process. J. Mater. Process. Technol. 77:17-24

13. Ohring S, Lugt HJ (1999) Numerical simulation of a timedependent 3-D GMA weld pool due to a moving arc. Weld. J. $78: 416 s-424 s$

14. Kim CH, Zhang W, DebRoy T (2003) Modeling of temperature field and solidified surface profile during gas-metal arc fillet welding. J. Appl. Phys. 94:2667-2679

15. Choi SK, Ko SH, Yoo CD, Kim YS (1998) Dynamic simulation of metal transfer in GMAW. Part 2. Short-circuit transfer modes. Weld. J. 77(1):45s-51s

16. Ko SH, Farson DF, Choi SK, Yoo CD (2000) Mathematical modeling of the dynamic behavior of GTA weld pools. Metall. Mater. Trans. B 31:1465-1473

17. Cao Z, Yang Z, Chen XL (2004) Three-dimensional simulation of transient GMA weld pool with free surface. Weld. J. 83(6):169s$176 \mathrm{~s}$

18. Hu J, Tsai HL (2007) Heat and mass transfer in gas metal arc welding. Part II. The metal. Int. J. Heat Mass Transf. 50:808-820

19. Kim RH, Na SJ (2010) A study on the welding current in butt joint P-GMA welding with acute groove angles. J. Weld. Join. 28(4):5560

20. Lee SH, Na SJ (2010) A study on the arc characteristics and weld pool analysis of GHTAW under the space environment. J. Weld. Join. 28(4):67-72

21. Kiran DV, Cho D-W, Song W-H, Na S-J (2015) Arc interaction and molten pool behavior in the three wire submerged arc welding process. Int. J. Heat Mass Transf. 87:327-340

22. Bang HS, Bang HS, Kim YC, Joo SM, Joa SW, Ro CS (2009) Influence of welding residual stress on the mechanical behavior of 
externally loaded dissimilar SS400-STS304 steel weldment. J. Weld. 27(5):34-41

23. Cho W-I, Na S-J, Thomy C, Vollertsen F (2012) Numerical simulation of molten pool dynamics in high power disk laser welding. J. Mater. Process. Technol. 212:262-275

24. Cho W-I, Na S-J (2020) Impact of wavelengths of $\mathrm{CO}_{2}$, disk, and green lasers on fusion zone shape in laser welding of steel. J. Weld. Join. 38(3):235-240

25. Cho MH, Lim YC, Farson DF (2006) Simulation of weld pool dynamics in the stationary pulsed gas metal arc welding process and final weld shape. Weld. J. 85(12):271s-283s

26. Voller VR, Prakash C (1987) A fixed grid numerical modelling methodology for convection-diffusion mushy region phasechange problems. Int. J. Heat Mass Transf. 30:1709-1719

27. Lin ML, Eagar TW (1986) Pressures produced by gas tungsten arcs. Metall. Mater. Trans. B 17(3):601-607
28. Sahoo P, Debroy T, McNallan MJ (1988) Surface tension of binary metal-surface active solute systems under conditions relevant to welding metallurgy. Metall. Trans. B 19(3):483-491

29. Phares DJ, Smedley GT, Flagan RC (2000) The wall shear stress produced by the normal impingement of a jet on a flat surface. $\mathrm{J}$. Fluid Mech. 418:351-375

30. Kou S, Sun DK (1985) Fluid flow and weld penetration in stationary arc welds. Metall. Trans. A 16:203-213

31. Cho W-I (2012) A numerical study on molten pool behavior in laser-arc hybrid welding processes. Ph. D. Dissertation, KAIST, Daejeon, Korea, 10-48

Publisher's note Springer Nature remains neutral with regard to jurisdictional claims in published maps and institutional affiliations. 